\title{
A Serological Study in Response to People at Occupational Risk of Rabies Virus Exposure in Nepal
}

\author{
Ganesh Raj Pant ${ }^{1^{*}}$, Arjun Raj Pant ${ }^{2}$, Bol Raj Acharya ${ }^{1}$, Manish Man Shrestha ${ }^{1}$, Vivek Pant ${ }^{3}$, Nayana Pant ${ }^{3}$ and Dwij Raj Bhatta ${ }^{4}$ \\ ${ }^{1}$ Rabies Vaccine Production Laboratory, Tripureshwor, Nepal \\ ${ }^{2}$ Sukraraj Tropical Hospital, Teku, Nepal \\ ${ }^{3}$ Institute of Medicine, TU, Maharajgunj, Nepal \\ ${ }^{4}$ Central Department of Microbiology, TU, Kirtipur, Nepal
}

*Corresponding author: Ganesh Raj Pant, Rabies V accine Production Laboratory, T ripureshwor, AFU, Chitawn, Nepal, T el: 01-4109753; E-mail: pantganesh@hotmail.com

Received date: March 01, 2016; Accepted date: March 15, 2016; Published date: March 18, 2016

Copyright: () 2015 Pant GR, et al. This is an open-access article distributed under the terms of the Creative Commons Attribution License, which permits unrestricted use, distribution, and reproduction in any medium, provided the original author and source are credited.

\begin{abstract}
A serological study to know the antibody titer against rabies virus in human beings, who are at occupational risk, was conducted in Nepal in 2014. A total 44 serum samples were collected out of which 21 samples were collected from medical professionals (working at Sukraraj Tropical Hospital) and 23 were collected from veterinary professionals (working at Central Veterinary Hospital, Central Veterinary Laboratory and Rabies Vaccine Production Laboratory) in Kathmandu. Among the 44 samples, 4 were collected from unvaccinated persons. The other 40 people sampled were vaccinated with inactivated rabies vaccine. All samples were subjected to the Rabies Fluorescent Focus Inhibition Test (RFFIT) test at Centre for Disease Control and Prevention, Atlanta, USA. The antibody level of 7 persons was found to be less than the WHO recommended titer of $0.5 \mathrm{IU} / \mathrm{ml}$. Six medical professionals and one veterinary professional had a low rabies virus neutralizing antibody titer. The 4 samples collected from unvaccinated persons, and 3 collected from vaccinated persons had a titer below $0.5 \mathrm{IU} / \mathrm{ml}$. This study shows that medical and veterinary professionals who are responsible to nurse or handle rabies patients, rabid animals or rabies virus are still at high risk. This underscores the importance of recommendations for regular serological testing of occupationally exposed individuals and vaccinating booster dose when necessary.
\end{abstract}

\section{Introduction}

Rabies is endemic and priority zoonotic disease in Nepal. The death of 200 [1], human being and 300 animals [2], per year has been reported in this country. The disease has been confirmed in cattle, buffaloes, goats, alpaca, dogs and mongoose [3]. Rabies occurs throughout the year and $\operatorname{dog}$ is the principle vector for the transmission of disease. Rabies Vaccine Laboratory in Kathmandu produces 50, 000 doses of cell culture vaccine for animal use whereas vaccine for human use is imported from other countries [3]. Health authority purchased 300,000 doses expending 1 million USD every year to purchase inactivated cell culture rabies vaccine for human use (personal contact with EDCD). In 2012, 334,737 doses of cell culture rabies vaccine were purchased by Epidemiology and Disease Control Division, the Department of Health Service. Vaccine is not available to all victims at risk in country side therefore the case fatality is higher [4]. More than 45,000 people receive post exposure vaccination annually in Nepal. Number of dog bitten cases per month coming to Sukraraj Tropical Hospital (STH) for post exposure treatment is 1520 and in average 50 cases receives post exposure rabies vaccine daily in this hospital (Personal contact with STH Hospital).

Human or animal health workers, in contact with rabid animal or patient or rabies virus are at high risk of rabies infection. Therefore pre exposure rabies vaccine has been recommended by World Health Organization (WHO) for medical peoples, veterinarian and laboratory personals. The immunization protocol includes three injections, e.g. at days 0,7 , and 28. The serological evaluation of immunization is made 1-3 weeks after the last injection, and checked every 6 months in the case of laboratory workers or every 2 years for other diagnosticians. Booster vaccination must be given when the titer falls below 0.5 International Units (IU) per $\mathrm{ml}$. In the absence of serological monitoring, the vaccination regimen should consist of a booster vaccination at 1 year and thereafter every $1-3$ years $[5,6]$. Therefore the antibodies tire in response of rabies vaccine in vaccinated people or animal should be tested periodically by performing Rabies Fluorescent Focus Inhibition Test (RFFIT) after vaccination to avoid unnecessary vaccination and to reduce the risk of rabies infection. In this study we have measured antibody tire against rabies vaccine in professional people who have high risk hazard of Rabies.

\section{Methodology}

Blood samples were collected from 44 persons (13 female and 31 male) after getting oral consent in 2014. Sampled persons were 21 medical professional and 23 veterinary professional having occupational risk of rabies. Among medical professional 4 were doctors and 17 were technicians (paramedical) working at Sukraraj Tropical Hospital, Kathmandu. Among veterinary professional 9 working at Central Veterinary Hospital, 7 working at Central Veterinary Laboratory and 7 working at Rabies Vaccine Production Laboratory in Kathmandu. All 44 samples person were 28-58 years old. Among 44 collected samples, 4 were from unvaccinated persons and rest was from vaccinated persons in different time. Serum was separated labeled accordingly and stored at $-20^{\circ} \mathrm{C}$ in refrigerator. The description of samples was presented in table 1. Samples were packed and transferred to Centre of Disease and Prevention Rabies 
Citation: Pant GR, Pant AR, Acharya BR, Shrestha MM, Pant V, et al. (2016) A Serological Study in Response to People at Occupational Risk of Rabies Virus Exposure in Nepal. J Vaccines Vaccin 7: 312. doi:10.4172/2157-7560.1000312

Page 2 of 3

Laboratory, Atlanta USA according to IATA instruction. The serum samples were subjected to RFFIT according to protocol described by World Health Organization (1996).

\section{Results and Discussion}

The test revealed that $15.9 \%$ of tested samples had antibody titer $0.043 \mathrm{IU} / \mathrm{ml}$ below than $\mathrm{WHO}$ recommendation $0.5 \mathrm{IU} / \mathrm{ml}$ serum and $84.1 \%$ of tested samples had adequate titer ranging from 1.1 to 3316 $\mathrm{IU} / \mathrm{ml}$. Out of 40 sample collected from vaccinated person $7.5 \%$ had low antibody titer. The result of RFFIT has been presented in table 1. The variation of antibody titer was directly related to the number or frequency of dose, type of vaccine and duration between vaccination time and time of sample collection. Six medical professional and one veterinary professional had low level of titer. The low level of titer in 4 unvaccinated medical professional was normal and expected in control samples. Sample No. 1 revealed low titer because sampled person had taken nerve tissue post exposure vaccine 15 years ago. Low antibody titer of sample No. 8 (medical professional) and sample No. 29 (veterinary professional) might be due to lack of booster dose both of them had taken pre-exposure vaccination 1-3 years ago. However other factor such as host ability to immune response, quality of vaccine and health status may influence the production of antibody titer in host [7]. Sample No. 7 had highest titer $3396 \mathrm{IU} / \mathrm{ml}$ because

Sampled person had taken pre exposure cell culture inactivated vaccine and again booster dose 3 month ago. All 40 vaccinated people had taken inactivated cell culture vaccine except sample No. 1 and all sampled person with adequate antibody titer had taken booster in addition to pre or post exposure vaccine. This study showed that $15.9 \%$ of sampled professional were working at risk at Sukraraj Tropical Hospital and Central Veterinary Hospital were rabid patient were examined and treated. Among 7, 5 were female and 2 were male by sex. Therefore pre exposure vaccination and periodic sero-monitoring of antibody titer and administration of booster for person working at risk is urgent which is lacking in Nepal. WHO and World Organization for Animal Health has also recommended such preventive measures to be adopted by people at risk of rabies who work in medical and veterinary hospital or laboratories $[4,8]$.

\begin{tabular}{|l|l|l|l|l|}
\hline $\begin{array}{l}\text { Sample } \\
\text { No. }\end{array}$ & Sex & Titer & IU/mI & Recommendations \\
\hline 1 & Male & $<5$ & $<0.043$ & Recommendation boost \\
\hline 2 & Female & 6000 & 52 & Adequate \\
\hline 3 & Male & 2200 & 19 & Adequate \\
\hline 4 & Female & 45 & 0.39 & Consider boost \\
\hline 5 & Male & 1200 & 10 & Adequate \\
\hline 6 & Male & 1100 & 9.6 & Adequate \\
\hline 7 & Female & $>390625$ & $>3396$ & Adequate \\
\hline 8 & Female & 21 & 0.18 & Recommended boost \\
\hline 9 & Female & $<5$ & $<0.043$ & Recommended boost \\
\hline 10 & Male & 15625 & $>136$ & Adequate \\
\hline 11 & Female & $<5$ & $<0.043$ & Recommended boost \\
\hline 12 & Male & 1900 & 16 & Adequate \\
\hline
\end{tabular}

\begin{tabular}{|c|c|c|c|c|}
\hline 13 & Male & 145 & 1.3 & Adequate \\
\hline 14 & Male & 230 & 2 & Adequate \\
\hline 15 & Male & 1100 & 9.6 & Adequate \\
\hline 16 & Female & 1100 & 9.6 & Adequate \\
\hline 17 & Male & 5100 & 44 & Adequate \\
\hline 18 & Female & $<5$ & $<0.043$ & Recommended boost \\
\hline 19 & Male & 1500 & 13 & Adequate \\
\hline 20 & Male & 1300 & 11 & Adequate \\
\hline 21 & Female & 280 & 2.4 & Adequate \\
\hline 22 & Male & 1300 & 11 & Adequate \\
\hline 23 & Male & 3125 & 50 & Adequate \\
\hline 24 & Male & 250 & 8.6 & Adequate \\
\hline 25 & Female & 270 & 4.3 & Adequate \\
\hline 26 & Male & 3600 & 58 & Adequate \\
\hline 27 & Male & 1300 & 21 & Adequate \\
\hline 28 & Female & 70 & 1.1 & Adequate \\
\hline 29 & Male & 7 & 0.11 & Recommended boost \\
\hline 30 & Male & 1800 & 29 & Adequate \\
\hline 31 & Male & 4200 & 67 & Adequate \\
\hline 32 & Male & 4600 & 74 & Adequate \\
\hline 33 & Male & 4200 & 67 & Adequate \\
\hline 34 & Female & 270 & 4.3 & Adequate \\
\hline 35 & Male & 2700 & 43 & Adequate \\
\hline 36 & Male & 1900 & 30 & Adequate \\
\hline 37 & Male & 110 & 1.8 & Adequate \\
\hline 38 & Male & 1100 & 18 & Adequate \\
\hline 39 & Female & 450 & 8.6 & Adequate \\
\hline 40 & Male & 12000 & 192 & Adequate \\
\hline 41 & Male & 1300 & 21 & Adequate \\
\hline 42 & Male & 5100 & 82 & Adequate \\
\hline 43 & Male & 210 & 3.4 & Adequate \\
\hline 44 & Male & 1900 & 30 & Adequate \\
\hline
\end{tabular}

Table 1: Result of RFFIT of human serum samples collected from Nepal in 2014.

\section{Conclusion}

All medical or veterinary professional who are at risk of rabies infection are recommended to take pre-exposure inactivated cell culture rabies vaccine. Antibody titer in vaccinated persons should be 
Citation: Pant GR, Pant AR, Acharya BR, Shrestha MM, Pant V, et al. (2016) A Serological Study in Response to People at Occupational Risk of Rabies Virus Exposure in Nepal. J Vaccines Vaccin 7: 312. doi:10.4172/2157-7560.1000312

Page 3 of 3

tested periodically to ensure the antibody level of protection and to inject booster dose of vaccine accordingly.

\section{Acknowledgement}

Authors would like to acknowledge Dr. Todd Smith and Dr. Ashutosh Wadhwa, CDC, Atlanta, USA for their technical support and help conducting RFFIT test of Nepalese human serum samples at their laboratory and providing us result. Authors would like to thank CDC, Rabies Laboratory, Atlanta USA. The help of Sukraraj Tropical Hospital, Central Veterinary Laboratory, Central Veterinary Hospital and Rabies Vaccine Production Laboratory in Kathmandu for providing serum samples is highly appreciated.

\section{References}

1. Pant GR, Acharya BR (2010) Rabies: Dangerous Fatal Disease. Veterinary Quarterly Bulletin Nepal Veterinary Association. Plos one 9: 39.

2. Veterinary Epidemiology Center (2013) Annual Epidemiological Bulletin. January-December, pp: 13.
3. Pant GR (2013) Progress on rabies vaccine production in Nepal, Modern Vaccine and Adjuvant Formulation 2013 international conference held in Lausanne Switzerland. Hum Vaccin Immunother 9: 2007-2008.

4. Pant GR, Horton D, Fooks AR (2013) Antibody response in ruminants against inactivated cell culture rabies vaccine in Nepal, Proceeding of scientific presentation and conference information, 11th Conference of Nepal Veterinary Association. pp: 10.

5. World Health Organization Expert Committee on Rabies (2005) Eighth Report. World Health Organization, WHO Technical Report Series, Switzerland, pp: 1-87.

6. World Health Organization (2010) Current strategies for human rabies pre and post-exposure prophylaxis, Fact Sheet updated September 3, 2010, World Health Organization, Geneva.

7. Pant GR, Horton DL, Dahal M, Rai JN, Ide S, et al. (2011) Characterization of rabies virus from a human case in Nepal. Archives of Virology 156: 681-684.

8. World Organization for Animal Health, (1996) Rabies, Manual of diagnostic test and vaccine (3rd edn), OIE, Paris, France pp: 207-217. 